\title{
Applicability of gypsum in selective removal of anionic dye molecules from aqueous medium
}

\author{
Mohammad Jobaer Hassan ${ }^{1} \cdot$ Md. Fahamidul Islam ${ }^{1} \cdot$ Nahida Akter $^{2,3} \cdot$ Md. Nizam Uddin ${ }^{1} \cdot$ Abrar Yasir Abir $^{1}$. \\ Sami Ben Aoun ${ }^{4}$. Mohammad A. Hasnat ${ }^{1,5}$ (i)
}

Received: 23 May 2020 / Accepted: 1 December 2020 / Published online: 2 January 2021

(C) The Author(s) 2021

\begin{abstract}
This article describes how selectively anionic organic molecules could be removed from aqueous medium using naturally available gypsum (GS) adsorbent. Gypsum $\left(\mathrm{CaSO}_{4} \cdot 2 \mathrm{H}_{2} \mathrm{O}\right)$ shows strong interactions with anionic dye molecules while it dos not show any affinity towards cationic dye molecules. We have shown the removal efficiency of gypsum taking chlorazole yellow (anionic dye) and methylene blue (cationic dye) as examples of adsorbates. The GS has been to be even more effective than activated carbon in attaining chlorazole yellow (CY) removal. Three well-known kinetic equations e.g. pseudo-firstorder, pseudo-second order and intraparticle diffusion were exploited to interpret the experimental data. Results show best fitting with second order kinetic process with excellent regression coefficient $\left(r^{2}=0.99\right)$ for the adsorption process. The equilibrium data were analyzed exploiting some adsorption isotherm models. It was apparent that the Freundlich isotherm model superbly fitted for CY dye adsorption process. And the maximum adsorption capacity, $Q_{\mathrm{m}}$, was obtained as $12.85 \mathrm{mg} \mathrm{g}^{-1}$ at room temperature. The negative values of Gibb's free energy change $\left(\Delta G^{\circ}\right)$ suggests that the $\mathrm{CY}$ dye molecule adsorption process is spontaneous in nature. Moreover, negative enthalpy change $\left(\Delta H^{\circ}\right)$ indicates the exothermic nature of the adsorption process. The outcome could be exploited where anionic organic molecules are required to be separated, selectively.
\end{abstract}

Keywords Adsorption $\cdot$ Chlorazol yellow $\cdot$ Environmental $\cdot$ Kinetics $\cdot$ Equilibrium isotherm $\cdot$ Gypsum

\section{Introduction}

Nowadays, the increasing world population has created exponent of an alarming contamination of surface and ground water. Over the years, textile and dyeing industries are playing an important role on economic and industrial

Mohammad A. Hasnat

mah-che@sust.edu; mahtazim@yahoo.com

1 Department of Chemistry, Graduate School of Physical Science, Shahjalal University of Science and Technology, Sylhet 3114, Bangladesh

2 Department of Chemistry, Barisal University, Barisal 8200, Bangladesh

3 School of Chemistry, University of Bristol, Bristol BS8 1TS, UK

4 Department of Chemistry, Faculty of Science, Taibah University, PO Box 30002, Al-Madinah Al-Munawarah, Kingdom of Saudi Arabia

5 Bangladesh Academy of Sciences, Agargaon, Dhaka 1207, Bangladesh revolutions around the world. Azo dyes, a class of colored organic pollutants, are used largely in textile, lather, paper and food industries and represent themain source of environmental contaminations. The dyeing process that is used in different industries produces a huge amount of wastewater, which are discharged directly into the aqueous mainstreams without any prior treatment. Thus, dye contamination of water causes a variety of environmental problems (Wang et al. 2005; Rao and Khan 2009; Magdy and Altaher 2018; Amin 2009; Malik 2004; Hameed 2009; Bhattacharya and Sharma 2005; Sivaraj et al. 2001; Kim et al. 2007; Tutem et al. 1998; Ho and Mckay 1999; Panday et al. 1985; Brown 1987) as they are non-biodegradable and highly toxic to aquatic creatures and carcinogenic to humans.

Removal of dye molecules from wastewater is extremely difficult and is also a most thought-provoking matter in environmental network and industries. Over the years, several methods such as coagulation, sedimentation, filtration, oxidation, adsorption (Islam et al. 2019; Youcef et al. 2019; Acar et al. 2015), photo catalytic degradation (Gotoh et al. 2004; Miyah et al. 2018), biodegradation (Hasnat et al. 2005) 
and electrochemical degradation (Fan et al. 2008; Azmi et al. 1998), are reported for the removal of organic pollutants/dyes. Due to the complexity of the matrix, none of the methods can remove pollutants successfully (Hasnat et al. 2015). Among these processes, adsorption has been explored to be most popular to decimate organic contaminants from wastewater in aspects of basic expense, simplicity of design, ease of act and insensitivity of toxic substances (Rahman 2011; Hasnat et al. 2007; Uddin et al. 2009). Adsorption process is one of the popular techniques used in liquid-phase to remove organic pollutants from wastewater because in most cases it produces high-quality treated effluent. Adsorption is the adhesion of adsorbates (the molecules, atoms, ions or biomolecules being accumulated) on the surface of the adsorbent (solid, liquid or gas phase) and creates a thin film on the adsorbent surface. Activated carbon, also called activated charcoal, is of great utility in order to decimate dyes/pollutants from wastewater because of its excellent properties (Caner et al. 2009; Kumar et al. 2018; Kannan and Sundaram 2001; Giannakoudakis et al. 2016; Goswami and Phukan 2017; Andersson et al. 2011; Ahmaruzzaman and Gupta 2011; Klimmek et al. 2001; Hameed et al. 2017). But, due to its high cost, the widespread use of activated carbon is restricted. Therefore, inexpensive, highly effective, easily available and obvious economical adsorbents are still required. It is well known that Bangladesh's economy is highly dependent on the garments-based industries. Consequently, lots of industries have been installed in this country. Following these many non-conventional and inexpensive inorganic compounds were utilized as adsorbents in the world e.g. zeolite, bentonite and siliceous materials (Rahman 2011). This study aims to investigate the use of commercially available gypsum for treating synthetic wastewater. Gypsum is an inorganic substance which has a high affinity to metal ions that led scientist to investigate the potential use of this environmentally friendly compound to remove toxic metal ions from wastewater (Rauf et al. 2009; Gou and Lua 2003; Mall et al. 2007; Ayrancci and Duman 2005; Yan et al. 2014; Mittal et al. 2008; Deniz and Saygideger 2010; Yagub et al. 2014; Nissinen et al. 2013). Naturally, GS particles possess positive charges (Raii et al. 2012). Thus, GS particles should have strong interactions towards anionic dye molecules. Considering this point, we assumed that GS could be applied to remove anionic dye molecules efficiently. Hence, in this study, we have selected gypsum to remove Chlorazol Yellow, an anionic dye, from synthetic wastewater as an example. Chlorazol Yellow (CY) is a heterocyclic organic compound, with a molecular formula $\mathrm{C}_{28} \mathrm{H}_{19} \mathrm{~N}_{5} \mathrm{O}_{6} \mathrm{Na}_{2} \mathrm{~S}_{4}$, and its molecular weight is $695.72 \mathrm{~g} / \mathrm{mol}$.

For this purpose, at first, adsorbing capability of GS towards CY molecules was compared with that of wellknown activated carbon. Next, detailed adsorbent related experiments were carried out under the impact of time of contact, solution $\mathrm{pH}$, amount of adsorbent, initial concentration of dye molecules and various anion effects. Different kinetic models e.g. pseudo-first order kinetic model, pseudo-second order kinetic model and intra-particle diffusion model, in addition to isotherm models given by Langmuir, Freundlich and Temkin were investigated. Finally, the adsorption was assessed by characterizing the adsorbent surface with Scanning Electron Microscopy (SEM).

\section{Experimental}

\section{Materials and instruments}

All the general chemicals were of analytical grade received from Merck, Germany and were used without further purifications. The main chemical, Chlorazol Yellow (CY) dye was supplied by Philip Harris Limited, Shenstone, England. The adsorbent, gypsum, was received from the responsible authority of Lafarge Surma Cement Ltd., Chatak, Sunamgonj, Sylhet (Bangladesh). It is to be noted that the sample was collected with permission letter (see supplementary file) given by the authority specifying appropriate permission for this study. The UV visible spectral changes were monitored using Avaspec, Spectrophtometer (Netherlands). The morphology of the adsorbed surface was analyzed employing a scanning electron microscope (SEM) (JSM-760F, Japan).

\section{Batch adsorption experiment}

The adsorption related experiments were monitored by means of UV-visible spectroscopy. A CY solution exhibits absorption maxima $\lambda_{\max }=390 \mathrm{~nm}$. To determine the concentration of CY molecules, absorbance was measured before and after adsorption at this absorption maxima. At first, the required amounts of CY and gypsum were taken in a conical flask such that the total volume was $25 \mathrm{ml}$. In this way a series of mixtures were prepared by varying their composition. The solutions as prepared were stirred mechanically using magnetic bars rotated at a speed of $200 \mathrm{rpm}$. The experiments were performed at room temperature $\left(25 \pm 1.0^{\circ} \mathrm{C}\right)$. In order to monitor the concentration change, $2 \mathrm{ml}$ solution was withdrawn periodically and after measurement the solution was returned to the reactor so that total volume of the reactor remained constant throughout the entire period of the experiments. When necessary, the $\mathrm{pH}$ of the reaction mixture was adjusted by adding dilute solutions of hydrochloric acid or sodium hydroxide.

The quantity of the dye removal (DR) in terms of percentage was evaluated by applying the following equation (Rahman et al. 2014; Akter et al. 2016): 
$\% \mathrm{DR}=\frac{A_{\mathrm{o}}-A_{\mathrm{t}}}{A_{\mathrm{o}}} \times 100$

where $A_{\mathrm{o}}$ and $A_{\mathrm{t}}$ represent the absorbance of CY at the beginning of the experiment and after a certain time period, respectively.

The amount of adsorption $q_{\mathrm{t}}\left(\mathrm{mg} \mathrm{g}^{-1}\right)$ at time $\mathrm{t}$, was calculated by the following relation (Rahman et al. 2014; Akter et al. 2016):

$q_{\mathrm{t}}=\frac{\Delta C}{M} \times V$

Here, $\Delta C\left(\mathrm{mg} \mathrm{L}^{-1}\right)$ refers to the change in $\mathrm{CY}$ concentration after a stipulated time period which was determined using Beer-Lambert law, $V(=0.025 \mathrm{~L})$ is the volume of the solution, and ' $M$ ' is the mass ( $\mathrm{g}$ ) of adsorbent gypsum.

The amount of $\mathrm{CY}$ removed at equilibrium due to adsorption $q_{\mathrm{e}}$ (mg. $\mathrm{g}^{-1}$ ) was calculated by means of Eq. (3) (Rahman et al. 2014; Akter et al. 2016)

$q_{\mathrm{e}}=\frac{\Delta C_{\mathrm{e}}}{M} \times V$

$\Delta C_{\mathrm{e}}\left(\mathrm{mg} \mathrm{L}^{-1}\right)$ being the change in $\mathrm{CY}$ concentration at equilibrium. Meanwhile, the standard error of the mean $\left(S_{\mathrm{a}}\right)$ was estimated using (Rahman et al. 2014)

$S_{\mathrm{a}}=\frac{\mathrm{SD}}{\sqrt{N}}$

SD and $N$ being standard deviation and number of experiments repeated, respectively. The SD values of the observations were evaluated using the following statistical relationship (Rahman et al. 2014):

$\mathrm{SD}=\sqrt{\frac{1}{N} \sum_{i=1}^{N}\left(x_{i}-\bar{x}\right)^{2}}$

where, $x_{i}\left(x_{1}, x_{2}, x_{3} \ldots x_{N}\right)$ are the observed quantities of the sample's items, $\mathrm{N}$ is the number of observations, and $\bar{x}$ is the mean value of the observations.
The Chemical Oxygen Demand (COD) of the CY solution was determined before and after the adsorption process following the method prescribed by American Public Health Association (APHA) (Arami et al. 2006). For this purpose, the following equation was used for determination of $\% \mathrm{COD}$ reduction (Akter et al. 2016)

$\% \mathrm{COD}$ reduction $=\frac{\mathrm{COD}_{\text {ini }}-\mathrm{COD}_{\text {eqm }}}{\mathrm{COD}_{\text {ini }}} \times 100$

\section{Results and discussion}

\section{Relative adsorption by activated carbon and gypsum}

Figure 1a shows the spectral changes of CY dye after $20 \mathrm{~min}$ long adsorption experiment under identical experimental conditions. It is clearly seen from this figure that the concentration of $\mathrm{CY}$ molecules fallen more rapidly when gypsum was used as adsorbent instead of activated carbon (AC). Consequently, after 140 min long experiment (shown in Fig. 1b), gypsum attained $84 \pm 0.2 \%$ removal of CY molecules from aqueous medium whereas at the same time, activated carbon removed only $58 \pm 0.2 \% \mathrm{CY}$ molecules. This observation suggests that gypsum materials have stronger interaction towards CY molecules than activated carbon. Thus, detailed adsorption related experiments were conducted using gypsum as adsorbent which are discussed in the following sections.

\section{Contact time effect}

Figure 2 shows the effect of contact time on $\mathrm{CY}$ ([CY] $\left.=70 \mathrm{mg} \mathrm{L}^{-1}\right)$ adsorption onto gypsum $\left(7 \mathrm{~g} \mathrm{~L}^{-1}\right)$. It is observed that the CY molecules rapidly adsorbed on gypsum in the first $20 \mathrm{~min}$ and under the experimental condition about $71.6 \pm 0.2 \% \mathrm{CY}$ was removed due to a huge number of active sites available on the adsorbent surface. The extent of adsorption increased gradually until $100 \mathrm{~min}$. contact
Fig. 1 Relative adsorption by gypsum (GS) and activated carbon (AC) in a $70 \mathrm{mg} \mathrm{L}^{-1}$ $\mathrm{CY}$ aqueous solution, adsorbent dose $=7 \mathrm{~g} \mathrm{~L}^{-1}$, rotational speed $=200 \mathrm{rpm}$, temperature $=25 \pm 1.0^{\circ} \mathrm{C}$. Contact time $=0$ to $20 \mathrm{~min}$. (a), and 0 to $140 \mathrm{~min}$. (b)
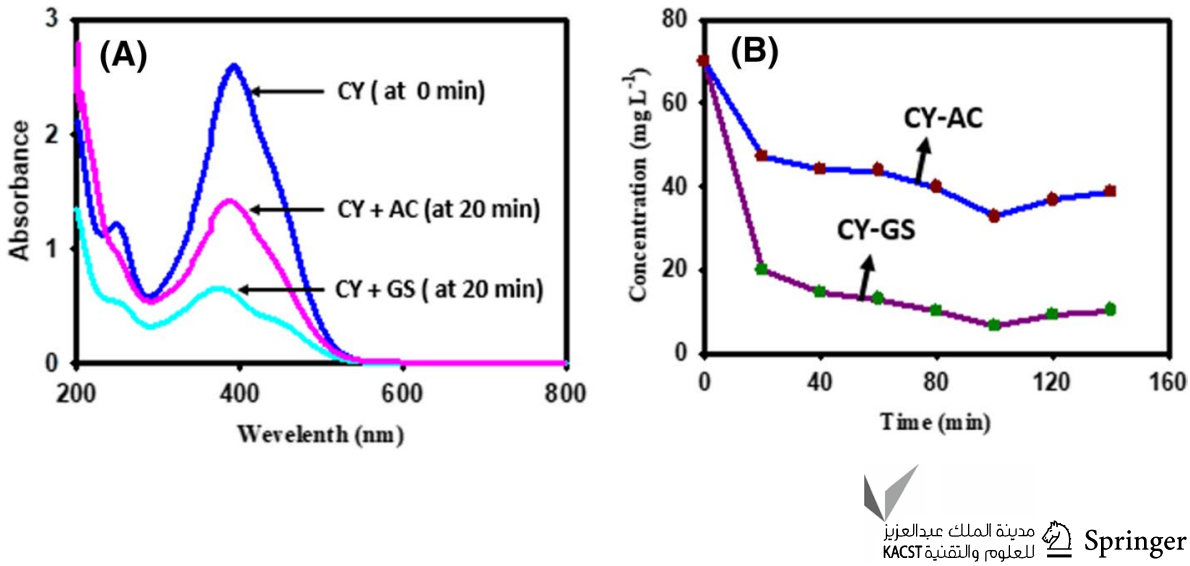


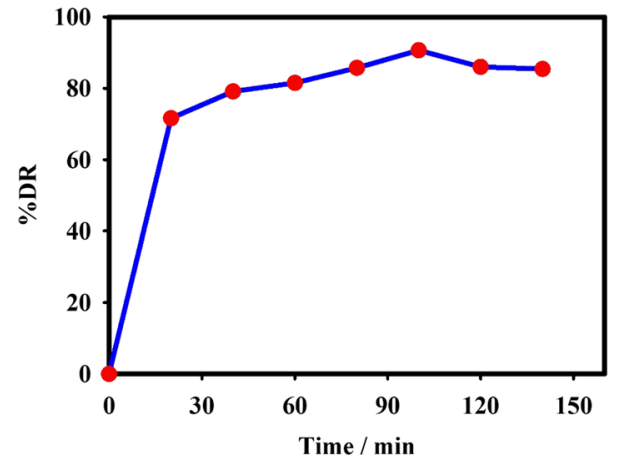

Fig. 2 Impact of contact time on CY dye removal efficiency by Gypsum in a $70 \mathrm{mg} \mathrm{L}^{-1} \mathrm{CY}$ aqueous solution, Gypsum dose $=7 \mathrm{~g} \mathrm{~L}^{-1}$, $\mathrm{pH}=7.0$, temperature $=25 \pm 1.0^{\circ} \mathrm{C}$, rotational speed $=200 \mathrm{rpm}$

time. Thus, this time point was designated as the time of equilibrium in the present research where the quantity of CY removal was found to be $90.7 \pm 0.2 \%$. However, above $100 \mathrm{~min}$, the \%DR was decreased. This observation may be interpreted by assuming that after saturation, the number of adsorption sites decreased which allowed less room for $\mathrm{CY}$ adsorption, which is reflected by the decrease of \%DR removal.

\section{Influence of gypsum dosage}

Figure 3 shows the influence of gypsum dosage on the $\% \mathrm{DR}$. It was found that \%DR increased with increase in gypsum dose up to $7 \mathrm{~g} . \mathrm{L}^{-1}$ at a fixed CY concentration of $70 \mathrm{mg} \mathrm{L}^{-1}$. For instance, when the gypsum dose was 1 g. $\mathrm{L}^{-1}$ the DR\% was estimated to be $79.8 \pm 0.2 \%$, which reached $91.7 \pm 0.2 \%$ when the adsorbent dose was $7 \mathrm{~g} \mathrm{~L}^{-1}$. It is worth mentioning that, as the gypsum dosage was increased active sites for $\mathrm{CY}$ adsorption also increased resulting in an increase of DR\%. However, the \%DR decreased as gypsum dose increased above $7 \mathrm{~g} \mathrm{~L}^{-1}$. Note that at $10 \mathrm{~g} \mathrm{~L}^{-1}$ of gypsum dosage, the

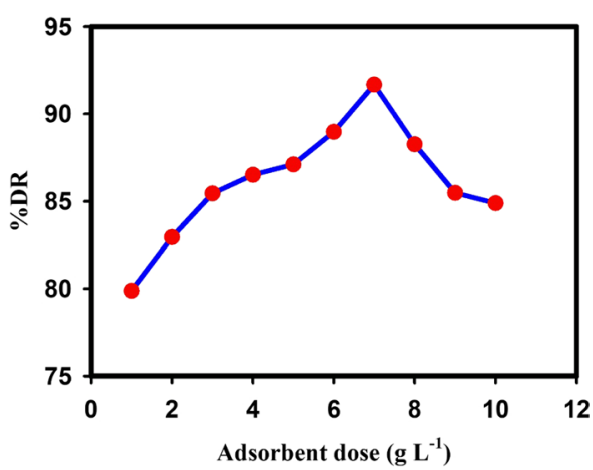

Fig. 3 Influence of Gypsum dosage on CY dye removal efficiency by Gypsum in a $70 \mathrm{mg} \mathrm{L}^{-1} \mathrm{CY}$ aqueous solution, $\mathrm{pH}=7.0$, contact time $=100 \mathrm{~min}$, temperature $=25 \pm 1.0^{\circ} \mathrm{C}$, rotational speed $=200 \mathrm{rpm}$
DR\% was found to be $85.02 \pm 0.2 \%$. Such a decrease of DR\% suggests that above $7 \mathrm{~g} \mathrm{~L}^{-1}$ of adsorbent dosage, gypsum particles aggregated with $\mathrm{CY}$ and, consequently, the surface activity decreased which gradually hindered CY adsorption onto the gypsum adsorbent.

From COD experiment, we observed that the COD of CY dye decreases with time for the adsorption onto Gypsum. On the other hand, the \%COD reduction increased as same as $\% \mathrm{DR}$ increased by passing time. It was found that the initial value of COD for $70 \mathrm{mg} \mathrm{L}^{-1} \mathrm{CY}$ was $412.2 \pm 0.2 \mathrm{mg} \mathrm{L}^{-1}$ and after $100 \mathrm{~min}$ the lowest COD value was $67.8 \pm 0.2 \mathrm{mg}$. $\mathrm{L}^{-1}$. This phenomenon ascertains that the CY dye highly adsorbed onto Gypsum by passing time 100 min. Beyond that, the COD value of CY dye increased with time because the surface of adsorbent was blocked by CY molecules. Figure 4 shows the \%COD reduction as time is increased. The similar phenomenon was investigated by other researchers (Arami et al. 2006).

\section{Influence of pH}

The adsorption of anionic CY dye was strongly affected by solution $\mathrm{pH}$. Figure 5 represents the adsorption behavior of $\mathrm{CY}$ molecules onto Gypsum granules within the $\mathrm{pH}$ range of 4-9. It can be seen from the plot that the highest \%DR was found to be $91.9 \pm 0.2$ at $\mathrm{pH}=7$. Below this $\mathrm{pH}$ value, the $\% \mathrm{DR}$ was found to decrease. This may be due to the fact that at lower $\mathrm{pH}$ values, $\mathrm{CY}$ molecules are protonated as well as gypsum particles also, perhaps, gain positive charges. Thus, a coulombic repulsive force might predominate at lower $\mathrm{pH}$ values leaving no room for $\mathrm{CY}$ adsorption onto the gypsum surface. Meanwhile, above $\mathrm{pH}$ 7.0, CY molecules become deprotonated and gypsum particles would bear negative charges. Thus, the similar polarity again repelled the dye molecules refraining them from being adsorbed onto the gypsum surface. The outcome of $\mathrm{pH}$ observation

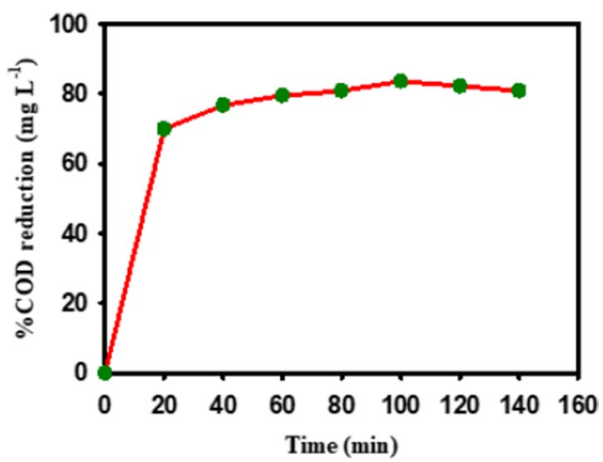

Fig. 4 Influence of time on \%COD reduction for the adsorption of CY onto Gypsum in a $70 \mathrm{mg} . \mathrm{L}-1$ at $\mathrm{CY}$ aqueous solution, Gypsum dose $=7 \mathrm{~g} \mathrm{~L}^{-1}, \mathrm{pH}=7.0$, temperature $=25 \pm 1.0{ }^{\circ} \mathrm{C}$, rotational speed $=200 \mathrm{rpm}$ 


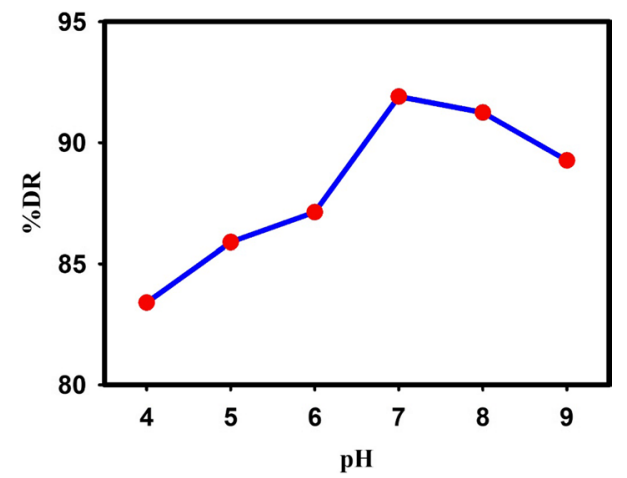

Fig. 5 Impact of solution $\mathrm{pH}$ on $\mathrm{CY}$ removal efficiency by Gypsum in a $70 \mathrm{mg} . \mathrm{L}-1$ at $\mathrm{CY}$ aqueous solution, Gypsum dose $=7 \mathrm{~g} \mathrm{~L}^{-1}$, temperature $=25 \pm 1.0{ }^{\circ} \mathrm{C}$, rotational speed $=200 \mathrm{rpm}$. time of con$\operatorname{tact}=100 \mathrm{~min}$

is consistent with literature reported for different processes (Silva et al. 2004; Rahman et al. 2014).

\section{Influence of $\mathrm{CY}$ concentration}

Change of initial CY concentration also influenced the adsorption behavior. Figure 6 delineates how CY concentration influenced adsorption quantity onto gypsum surface. This trend confirms that the \%DR decreased as the CY concentration was increased from 30 to $90 \mathrm{mg} \mathrm{L}^{-1}$. It is seen that when $\mathrm{CY}$ concentration was $30 \mathrm{mg} \mathrm{L}^{-1}$, the corresponding DR\% was found to be $99.4 \pm 0.2 \%$ for a dye concentration of $90 \mathrm{mg} \mathrm{L}^{-1}$ the, DR\% value decreased to $85.0 \pm 0.2 \%$. During this experiment, the adsorbent quantity was fixed, which means that the total adsorbing surface was also fixed. Consequently, as the CY concentration was increased, the surface to $\mathrm{CY}$ ratio decreased which resulted in a decrease of DR\% with increased CY concentration.

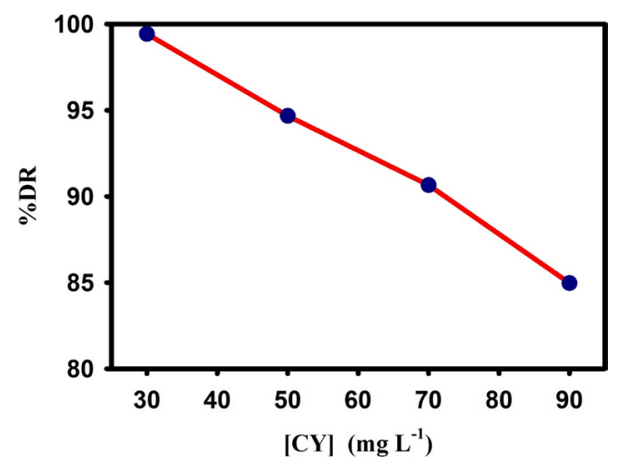

Fig. 6 Influence of initial CY concentration on the CY dye molecule removal efficiency by Gypsum at $\mathrm{pH}=7$, Gypsum dose $=7 \mathrm{~g} \mathrm{~L}^{-1}$, contact time $=100 \mathrm{~min}$, temperature $=25 \pm 1.0 \quad{ }^{\circ} \mathrm{C}$, rotational speed $=200 \mathrm{rpm}$

\section{Influence of electrolytes}

Wastewater may contain different salts apart from the organic pollutants. Thus, the influence of different electrolytes on CY dye adsorption onto Gypsum from water were investigated and the results are shown in Fig. 7. In the presence of different anions, mixtures of $70 \mathrm{mg} \mathrm{L}^{-1} \mathrm{CY}$ and $7 \mathrm{~g} \mathrm{~L}^{-1}$ Gypsum were prepared separately. While, in the absence of these anions, the \%DR was found to be $91.9 \pm 0.2 \%$, the \% DR was found to decrease in the order $\mathrm{F}^{-}>\mathrm{CO}_{3}^{2-}>\mathrm{SO}_{4}^{2-}>\mathrm{NO}_{3}^{-}>\mathrm{Cl}^{-}$. The analysis unveiled that $\% \mathrm{DR}$ was minimum in presence of fluoride ions. This observation concludes that $F^{-}$ions might have strong interactions with Gypsum surface which consequently decreased \%DR. Meanwhile, $\mathrm{Cl}^{-}$exhibited the least influence on $\mathrm{CY}$ removal because, perhaps, this anion had least interactions with Gypsum particles. Hence, in the presence of $\mathrm{Cl}^{-}$ions, maximum $\%$ DR was observed. Similar phenomenon was investigated and noticed by other researchers (Abbas et al. 2012).

\section{Adsorption kinetics}

Adsorption kinetics unveils the efficiency of an adsorbent pertaining to a specific adsorption process. In the present case, the time-dependent $\mathrm{CY}$ adsorption process on gypsum was fitted with different kinetic models such as pseudo-first order kinetics, pseudo-second order kinetics, and intraparticle diffusion model (Ahmad et al. 2007; Sengil and Ozacar 2008; Akter et al. 2016).

Note that the pseudo-first-order kinetic model may be expressed as follows

$\ln \left(q_{\mathrm{e}}-q_{\mathrm{t}}\right)=\ln q_{\mathrm{e}}-k_{1} t$

Here, $q_{\mathrm{e}}$ and $q_{\mathrm{t}}$ define the amount $\left(\mathrm{mg} \mathrm{g}^{-1}\right)$ of CY adsorption at equilibrium, and at time $t(\mathrm{~min})$, respectively, whereas $k_{1}\left(\mathrm{~min}^{-1}\right)$ refers the adsorption related rate constant relevant to

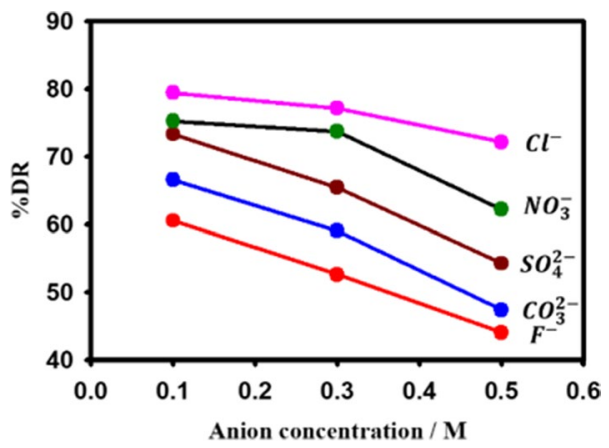

Fig. 7 Influence of anions on CY dye removal efficiency by Gypsum in a $70 \mathrm{mg} \mathrm{L}^{-1}$ at $\mathrm{CY}$ aqueous solution, Gypsum dose $=7 \mathrm{~g} \mathrm{~L}^{-1}$, $\mathrm{pH}=7.0$, temperature $=25 \pm 1.0^{\circ} \mathrm{C}$, rotational speed $=200 \mathrm{rpm}$. time of contact $=100 \mathrm{~min}$ 
pseudo-first-order adsorption. Figure 8 a shows $-\ln \left[1-\left(q_{\mathrm{t}} / q_{\mathrm{e}}\right)\right]$ variation with time and the associated constants are reported in Table 1. It was found that the value of the regression coefficient $\left(r^{2}\right)$ was equal to 0.89 . Such a smaller value of $r^{2}$ value suggests that the pseudo-first order model is not well-fitted with respect to CY adsorption on to gypsum (Ahmad et al. 2007). However, in many cases the adsorption kinetics cannot be described fully by using the above equation. Thus, we fitted our data with respect to the equation of pseudo-second order kinetic model (Eq. (8)) at constant temperature (Miyah et al. 2018; Ahmad et al. 2007).

$\frac{t}{q_{\mathrm{t}}}=\frac{1}{q_{\mathrm{e}}^{2} K_{2}}+\frac{1}{q_{\mathrm{e}}} t$

where, the symbols represent their usual meanings as mentioned earlier and $k_{2}\left(\mathrm{~g} \mathrm{mg}^{-1} \mathrm{~min}^{-1}\right.$.) denotes the rate constant of a process that follows pseudo-second order adsorption kinetics. The fitting of the CY adsorption data with this model is shown in Fig. 8b. The data is tabulated in Table 1. In this case, the value of the regression coefficient $\left(r^{2}\right)$ was found to be 0.99 . Thus, it is obvious that CY adsorption followed pseudo-second order kinetics. This means that both $\mathrm{CY}$ and gypsum equally control the adsorption process.

On the other hand, Intra-particle diffusion model is often employed to evaluate the adsorption process across the porous matrix. Thus, in accordance with reference (Miyah et al. 2018), we also fitted our data with relevant Eq. (9).

$q_{\mathrm{t}}=k_{\mathrm{i}} \sqrt{t}+f$
Table 1 Kinetic constants based on different kinetic models for the adsorption of CY dye onto Gypsum

\begin{tabular}{lll}
\hline Kinetic models & Rate constant & $r^{2}$ \\
\hline Pseudo-first-order & $K_{1}=3.28 \times 10^{-2} \mathrm{~min}^{-1}$ & 0.89 \\
Pseudo-second-order & $K_{2}=5.46 \times 10^{-2} \mathrm{~g} \mathrm{mg}^{-1} \mathrm{~min}^{-1}$ & 0.99 \\
Intra-particles diffusion & $K_{\mathrm{i}}=6.72 \times 10^{-1} \mathrm{mg} \mathrm{g}^{-1} \mathrm{~min}^{0.5}$ & 0.76 \\
\hline
\end{tabular}

Gypsum dose $=7 \mathrm{~g} \mathrm{~L}^{-1},[\mathrm{CY}]=70 \mathrm{mg} \mathrm{L}^{-1}, \mathrm{pH}=7.0$, time of contact $=100 \mathrm{~min}$., temperature $=25 \pm 1.0^{\circ} \mathrm{C}$, rotational speed $=200 \mathrm{rpm}$

where, $k_{\mathrm{i}}$ is the rate constant related to intra-particle diffusion, and ' $f$ ' indicates the thickness of boundary layer. Figure $8 \mathrm{c}$ represents a plot of $q_{\mathrm{t}}$ vs $t^{0.5}$ for CY adsorption onto Gypsum. It can be noted that the $\mathrm{CY}$ adsorption related data poorly fits with this model having a $r^{2}$ of 0.76 . At the same time, the $q_{\mathrm{t}}$ vs $t^{0.5}$ plot did not pass through the origin, which entails some degree of boundary layer control and the intra particle CY diffusion did not control the rate limiting step. Hence it infers more than one step of CY adsorption process onto gypsum. It is noteworthy that instantaneous adsorption occurs in the first sharper portion (a), second stage is a slower gradual adsorption (b) then finally decreasing stage (c).

\section{Adsorption isotherms}

An adsorption isotherm comprises information concerning the capacity of an adsorbent, types of interactions, adsorption layers etc. To obtain such information, several
Fig. 8 Kinetic Investigationplots of pseudo-first-order kinetic (a), pseudo-second-order kinetic (b), and Intra-particle diffusion for adsorption (c) of CY dye adsorption onto Gypsum in a $70 \mathrm{mg} \mathrm{L}^{-1} \mathrm{CY}$ aqueous solution, $\mathrm{pH}=7.0$, gypsum dose $=7 \mathrm{~g} \mathrm{~L}^{-1}$, time of contact $=100$ min., temperature $=25 \pm 1.0^{\circ} \mathrm{C}$, rotational speed $=200 \mathrm{rpm}$
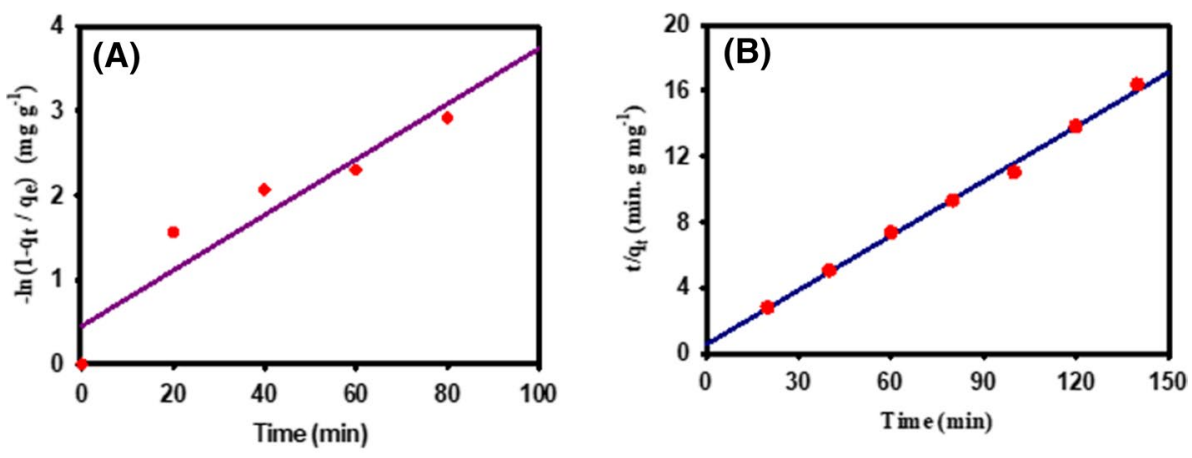

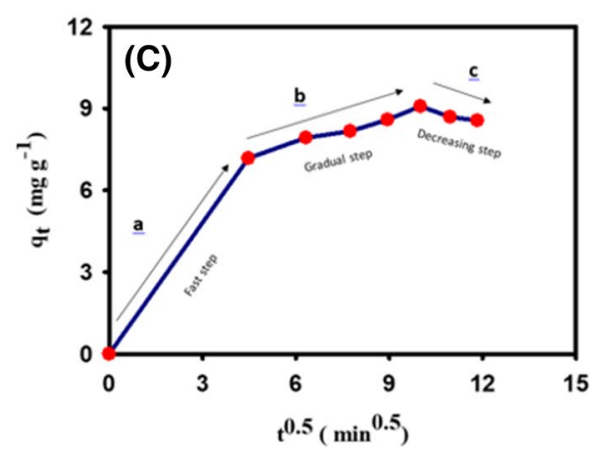


adsorption isotherm models are extensively studied depending on potential theory, thermodynamics and kinetics.

The Langmuir isotherm is often used to unveil the eventual monolayer formation by the adsorbate species onto an adsorbent under constant temperature condition (Ahmad et al. 2007). The linearized form of Langmuir isotherm can be expressed as per Eq. (10).

$\frac{C_{\mathrm{e}}}{q_{\mathrm{e}}}=\frac{1}{K_{\mathrm{L}} Q_{\mathrm{m}}}+\frac{C_{\mathrm{e}}}{Q_{\mathrm{m}}}$

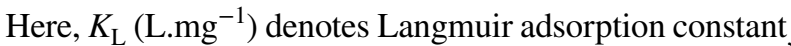
$Q_{\mathrm{m}}$ denotes optimum adsorption capacity in units of $\mathrm{mg} \mathrm{g}^{-1}$. Figure 9 a shows the $C_{\mathrm{e}} / q_{\mathrm{e}}$ vs $C_{\mathrm{e}}$ plot concerning adsorption of CY dye on gypsum adsorbent. The estimated values of the above-mentioned quantities are tabulated in Table 2. It was observed that the value of $Q_{\mathrm{m}}$ was evaluated as $12.85 \mathrm{mg} \mathrm{g}^{-1}$. This value of $Q_{\mathrm{m}}$ indicates the maximum amount of CY that could be removed by one gram of gypsum adsorbent.

Meanwhile, the Freundlich adsorption isotherm provides information considering multilayer adsorption on a heterogeneous surface in terms of logarithmic dependency of surface energies with surface coverage. This isotherm is often expressed as follows:

$\ln q_{\mathrm{e}}=\ln K_{\mathrm{f}}+\frac{1}{n} \ln C_{\mathrm{e}}$

Here, $K_{\mathrm{f}}\left(\mathrm{L} \mathrm{g}^{-1}\right)$ and ' $n$ ' $\left(\mathrm{g} \mathrm{L}^{-1}\right)$ designate the capability and intensity of the adsorption, respectively. The values of $\ln$
Table 2 Adsorption isotherms constants for different adsorption models for the adsorption of CY dye onto Gypsum

\begin{tabular}{llcl}
\hline Isotherm models & \multicolumn{2}{l}{ Adsorption Isotherm Constants } & $r^{2}$ \\
\hline Langmuir & $K_{\mathrm{L}}=0.11 \mathrm{~L} \mathrm{mg}^{-1}$ & $Q_{\mathrm{m}}=12.85 \mathrm{mg} \mathrm{g}^{-1}$ & 0.98 \\
Freundlich & $K_{\mathrm{F}}=1.97 \mathrm{~L} \mathrm{mg}^{-1}$ & $n=1.99$ & 0.99 \\
Temkin & $B_{1}=2.48$ & $K_{\mathrm{T}}=1.67$ & 0.96 \\
\hline
\end{tabular}

Gypsum dose $=7 \mathrm{~g} \mathrm{~L}^{-1},[\mathrm{CY}]=70 \mathrm{mg} \mathrm{L}^{-1}, \mathrm{pH}=7.0$, time of contact $=100$ min., temperature $=25 \pm 1.0^{\circ} \mathrm{C}$, rotational speed $=200 \mathrm{rpm}$

$q_{\mathrm{e}}$ is plotted against the values of $\ln C_{\mathrm{e}}$ and a linear graph is obtained (Fig. 9b). In Table 2, the constants evaluated from the graph are tabulated.

Finally, CY adsorption data were fitted with Temkin isotherm which provides information about adsorbent-adsorbate interaction on the basis of Heat of adsorption. It is considered that change in heat of adsorption of all molecules decreases linearly with the increase of adsorbate-adsorbent interactions (Mittal et al. 2008). The semi-logarithmic Temkin isotherm may be represented as follows:

$q_{\mathrm{e}}=B_{1} \ln \left(K_{\mathrm{T}} C_{\mathrm{e}}\right)$

In this equation, $K_{\mathrm{T}}$ denotes the equilibrium binding constant $\left(\mathrm{L} \mathrm{mg}^{-1}\right)$ and $B_{1}$ corresponds to the heat of adsorption. The $B_{1}$ is defined as $B_{1}=\frac{\mathrm{RT}}{b}$ which contains the universal gas constant $R\left(\mathrm{~J} \mathrm{~K}^{-1} \mathrm{~mol}^{-1}\right)$ and temperature $T$ in kelvin. A plot of $q_{\mathrm{e}}$ vs $\ln C_{\mathrm{e}}$ is shown in Fig. 9c and the constants
Fig. 9 Representation of adsorption isotherm models. Plot of $C \mathrm{e} / q \mathrm{e}$ with respect to Ce: Langmuir model (a), plot of $\ln q$ e against $\ln C \mathrm{e}$ : Freundlich model (b), plot of qe vs $\ln$ Ce: Temkin model (c) of CY dye adsorption onto Gypsum in a $70 \mathrm{mg} \mathrm{L}^{-1} \mathrm{CY}$ aqueous solution, $\mathrm{pH}=7.0$, gypsum dose $=7 \mathrm{~g} \mathrm{~L}^{-1}$, time of contact $=100 \mathrm{~min}$., temperature $=25 \pm 1.0^{\circ} \mathrm{C}$, rotational speed $=200 \mathrm{rpm}$
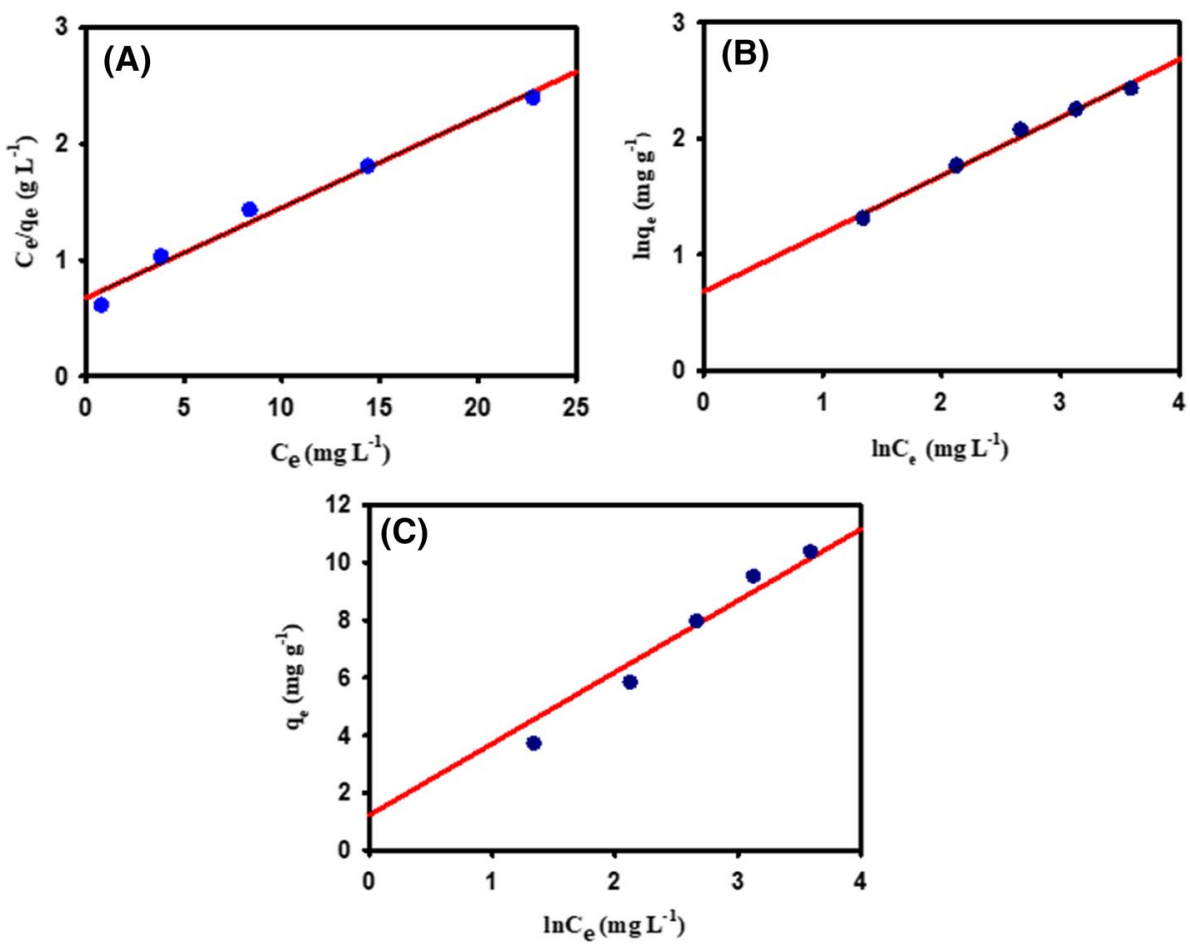
are tabulated in Table 2. The Freundlich isotherm gave the best correlation with the experimental data $\left(r^{2}=0.99\right)$. This observation indicates the heterogeneous nature of gypsum surface and the adsorption of $\mathrm{CY}$ proceeds by the formation of multilayer coverage at the outer surface of the gypsum.

\section{Adsorption thermodynamics}

The CY adsorption on gypsum has been identified as decreasing with the increase in temperature from 30 to $70{ }^{\circ} \mathrm{C}$ at pH 7.0 as shown in Fig. 10a. This observation is an indication of an involvement of exothermic process (Miyah et al. 2018). At the equilibrium, the Gibbs free energy change was estimated using Eq. (13) by evaluating equilibrium constant $\left(K_{L}\right)$ as is discussed in previous section for Langmuir isotherm.

$\Delta G^{\circ}=-\mathrm{RT} \ln K_{\mathrm{L}}$

In thermodynamics, the Gibbs free energy change is often employed to correlate with the enthalpy change $\left(\Delta H^{\circ}\right)$ and entropy change $\left(\Delta S^{\circ}\right)$ as per the following equation which is known as Van't Hoff equation.

$\ln K_{L}=\frac{\Delta S^{\circ}}{R}-\frac{\Delta H^{\circ}}{\mathrm{RT}}$

Plotting the values of $\ln K_{L}$ with respect to the reciprocal of temperatures, a linear graph is obtained (Fig. 10b). Then the thermodynamic quantities were evaluated from the slop and intercept and tabulated in Table 3.

Note that, irrespective of the temperature, $\Delta G^{\circ}$ values were found to be negative indicating that the CY dye adsorption onto gypsum is a spontaneous process. Additonally, lower temperatures favored the adsorption process, as supported by the negative sign of $\Delta H^{\circ}$ that was estimated as $-6.4 \mathrm{~J} \mathrm{~mol}^{-1}$ which implied the exothermic nature of CY dye adsorption onto gypsum. At the same time, the obtained value of $-18.34 \mathrm{~J} \mathrm{~mol}^{-1} \mathrm{~K}^{-1}$ for entropy change shows that the adsorption caused a decreasing disorder. Similar
Table 3 Thermodynamic parameters for the adsorption of CY dye onto Gypsum

\begin{tabular}{llll}
\hline $\mathrm{T} / \mathrm{K}$ & $\Delta \mathrm{G}^{\circ} / \mathrm{kJ} \mathrm{mol}^{-1}$ & $\Delta \mathrm{H}^{\circ} / \mathrm{J} \mathrm{mol}^{-1}$ & $\Delta \mathrm{S}^{\circ} / \mathrm{J} \mathrm{mol}^{-1} \mathrm{~K}^{-1}$ \\
\hline 303 & -0.8212 & & \\
313 & -0.5878 & & -18.34 \\
323 & -0.4404 & -6.4 & \\
333 & -0.2771 & & \\
343 & -0.0188 & & \\
\hline
\end{tabular}

Gypsum dose $=7$ g. $\mathrm{L}^{-1},[\mathrm{CY}]=70 \mathrm{mg} . \mathrm{L}^{-1}, \mathrm{pH}=7.0$, time of contact $=100 \mathrm{~min}$., rotational speed $=200 \mathrm{rpm}$

phenomenon was reported by other researchers (Akter et al. 2016) (Figs. 11, 12).

\section{Morphology}

Figure 11 shows the SEM images of Gypsum before and after adsorption of Chlorazol Yellow dye on GS particles. It can be seen that the surface of the Gypsum particles after adsorption became covered with sponge-like material. The clear difference between the two images of Gypsum before and after $\mathrm{CY}$ adsorption confirms that $\mathrm{CY}$ molecules were firmly adsorbed onto the Gypsum surface.

\section{Methylene blue adsorption onto gypsum}

Adsorption of a cationic dye, methylene blue, onto gypsum was studied and found that gypsum had better affinity for methylene blue $(\mathrm{MB})$ in acidic medium $(\mathrm{pH}=6)$ rather than in neutral medium $(\mathrm{pH}=7)$. The $\% \mathrm{DR}$ was $24 \pm 2.0 \%$ and $\leq 38 \pm 2.0 \%$ in neutral and acidic medium, respectively (Figure 12a). Whereas the \%DR of CY in the current study is found to be $\sim 92 \%$ in neutral medium under identical experimental conditions (Fig. 5). Figure 12b is a presentation of time-dependent removal of methylene blue by gypsum which shows that \%DR remains constant beyond 73 min after reaching a maximum \%DR of $26.3 \%$. On the contrary, the maximum \%DR was more than $90 \%$ for $\mathrm{CY}$ removal study (in Fig. 2). It is therefore clear that gypsum particles
Fig. 10 Plot of \%DR at different temperatures (a), and Van't Hoff's plot of lnK vs $1 / \mathrm{T}$ (b) of CY dye adsorption onto Gypsum in a $70 \mathrm{mg} \mathrm{L}^{-1} \mathrm{CY}$ aqueous solution, $\mathrm{pH}=7.0$, gypsum dose $=7$ g.L-1, time of contact $=100 \mathrm{~min}$., rotational speed $=200 \mathrm{rpm}$
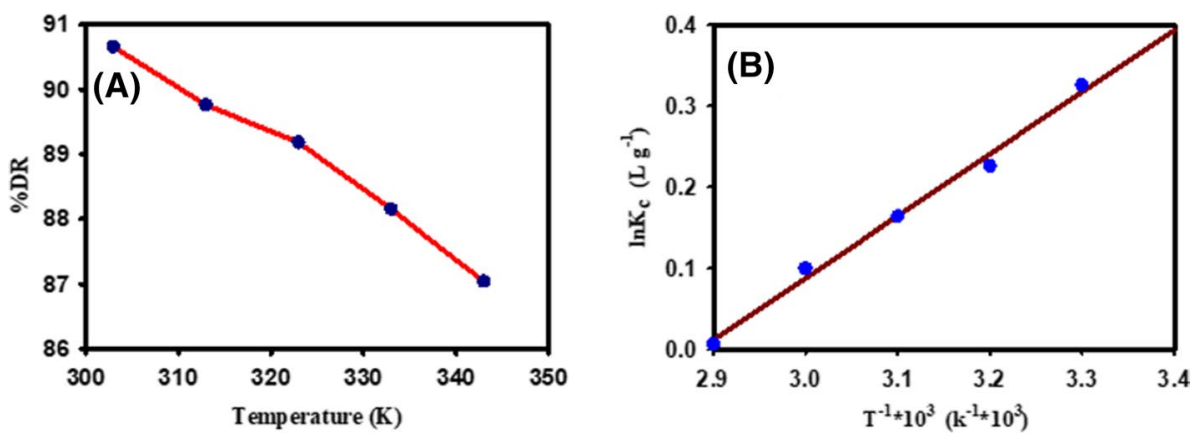

行 KACSTT 
Fig. 11 SEM images of pure Gypsum (a) and CY adsorbed Gypsum (b)
Fig. 12 Effect of $\mathrm{pH}$ (a) and time (b) on the \%DR of methylene blue by Gypsum in a $70 \mathrm{mg} \mathrm{L}^{-1} \mathrm{MB}$ aqueous solution, $\mathrm{pH}=7.0$, gypsum dose $=7 \mathrm{~g} \mathrm{~L}^{-1}$, time of contact $=90 \mathrm{~min}$., temperature $=25 \pm 1.0^{\circ} \mathrm{C}$, rotational speed $=200 \mathrm{rpm}$
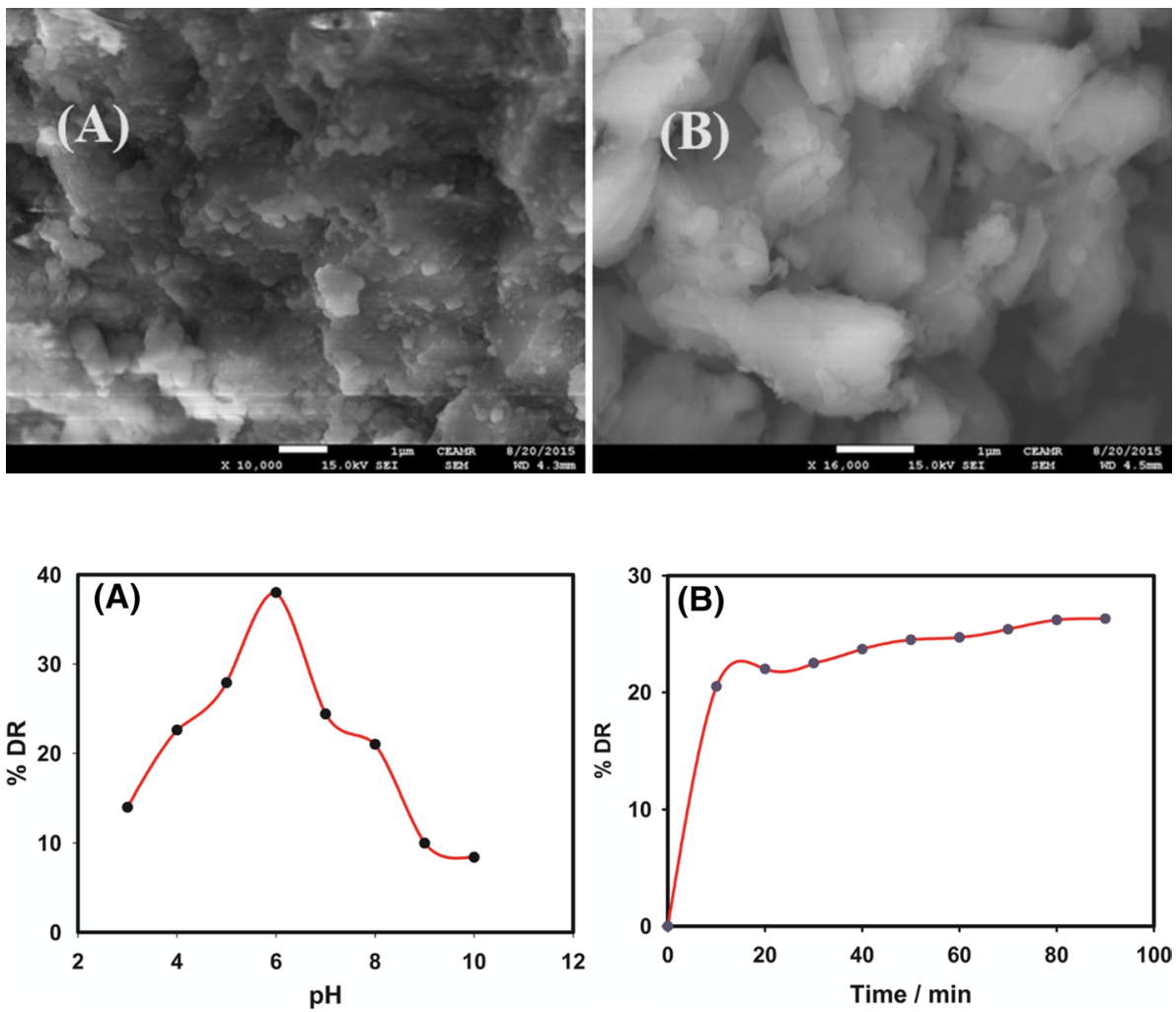

\section{Adsorption mechanism}

As described earlier, we tried to carry out experiments pertaining to adsorption of a cationic dye (methylene blue) onto GS particles but very limited adsorption was noticed at neutral medium. This observation confirms that GS particles carry positive charges as is reported in reference (Raii et al. 2012). Thus, the positive charge on GS particles impeded the adsorption of cationic methylene blue molecules due to electrostatic repulsive forces. Conversly, it is seen from Fig. 3 that $\mathrm{CY}$ molecules are highly adsorbed at $\mathrm{pH}$ 7.0. At acidic $\mathrm{pH}, \mathrm{CY}$ molecules become protonated, hence, poor attractive forces exist between the positively charged GS particles and the protonated $\mathrm{CY}$ molecules. Above $\mathrm{pH} 7.0$, the amount of positive charges on GS particles perhaps declined, reducing the attractive forces between GS and CY particles. At $\mathrm{pH}$ 7.0, optimum positive and negative charges on GS and CY particles, respectivelyinduced the strong attractions and by consequence effective adsorption occurs. This is schematically presented in Scheme 1.

\section{Conclusion}

Gypsum is a naturally abundant adsorbent and can be employed for adsorbing anionic dye molecules from aqueous medium selectively. In the present work, we have demonstrated how Chlorazol Yellow (CY), an anionic dye, could conditions. 


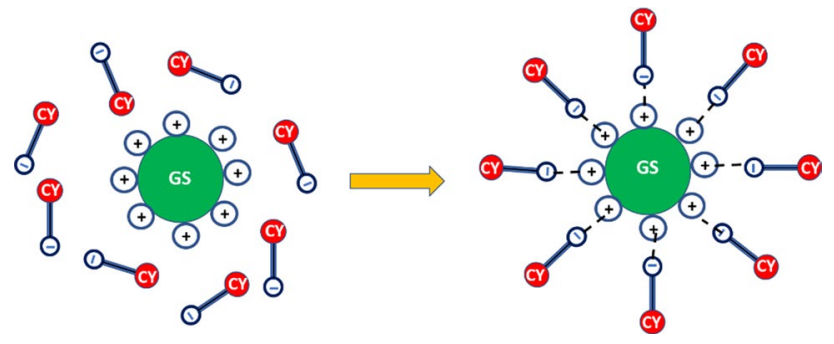

Scheme 1 Adsorption of CY molecules on GS particles via electrostatic attractions between CY and GS particles.

be selectively removed from water. Moreover, we have found that GS particles have poor adsorption affinity for methylene blue (a cationic dye) in neutral medium. It was observed that $\mathrm{CY}$ molecules are effectively removed at neutral $\mathrm{pH}$ and that fluoride ions are highly competitive with CY adsorption. A gypsum dosage of $7 \mathrm{~g} / \mathrm{L}$ is recommended for an efficient adsorption. The adsorption process follows pseudo-second order kinetics and could be best explained by Freundlich adsorption isotherm. The process is spontaneous and is less favorable at high temperatures. Based on kinetic, thermodynamic, and mechanistic investigations, it was suggested that gypsum can be effectively applied for the selective removal of anionic dyes (e.g. CY in the current study) in aqueous medium.

Funding The authors are indebted to TWAS for a research grant (2019_19-222 RG/CHE/AS_G) and SIDA. The ministry of Science and Technology, Bangladesh (project No ES 369) and SUST research center are also acknowledged for providing financial supports.

\section{Compliance with ethical standards}

Conflict of interest The authors declare that they have no conflict of interest.

Ethical Approval All procedures followed were in accordance with the ethical standards.

Open Access This article is licensed under a Creative Commons Attribution 4.0 International License, which permits use, sharing, adaptation, distribution and reproduction in any medium or format, as long as you give appropriate credit to the original author(s) and the source, provide a link to the Creative Commons licence, and indicate if changes were made. The images or other third party material in this article are included in the article's Creative Commons licence, unless indicated otherwise in a credit line to the material. If material is not included in the article's Creative Commons licence and your intended use is not permitted by statutory regulation or exceeds the permitted use, you will need to obtain permission directly from the copyright holder. To view a copy of this licence, visit http://creativecommons.org/licenses/by/4.0/.

\section{References}

Abbas A, Murtaza S, Shahid K, Munir M, Ayub R, Akber S (2012) Comparative study of adsorptive removal of congo red and brilliant green dyes from water using peanut shell. Middle East J Sci Res 11:828-832

Acar E, Ortaboy S, Atun G (2015) Adsorptive removal of thiazine dyes from aqueous solutions by oil shale and its oil processing residues: Characterization, equilibrium, kinetics and modeling studies. Chem Eng J 276:340-348

Ahmad A, Hameed B, Aziz N (2007) Adsorption of direct dye on palm ash: Kinetic and equilibrium modeling. J Hazard Mater 141:70-76

Ahmaruzzaman M, Gupta V (2011) Rice husk and its ash as low-cost adsorbents in water and wastewater treatment. Ind Eng Chem Res 50:13589-13613

Akter N, Hossain M, Hassan MJ et al (2016) Amine modified tannin gel for adsorptive removal of Brilliant Green dye. J Environ Chem Eng 4:1231-1241

Amin N (2009) Removal of direct blue-106 dye from aqueous solution using new activated carbons developed from pomegranate peel: Adsorption equilibrium and kinetics. J Hazard Mater 165:52-62

Andersson K, Eriksson M, Norgren M (2011) Removal of lignin from wastewater generated by mechanical pulping using activated charcoal and fly ash: adsorption isotherms and thermodynamics. Ind Eng Chem Res 50:7722-7732

Arami M, Limaee N, Mahmoodi N, Tabrizi N (2006) Equilibrium and kinetics studies for the adsorption of direct and acid dyes from aqueous solution by soy meal hull. J Hazard Mater 135:171-179

Ayrancci E, Duman O (2005) Adsorption behaviors of some phenolic compounds onto high specific area activated carbon cloth. J Hazard Mater 124:125-132

Azmi W, Sani R, Banerjee U (1998) Biodegradation of triphenylmethane dyes. Enzyme Microb Technol 22:185-191

Bhattacharya G, Sharma A (2005) Kinetics and thermodynamics of Methylene Blue adsorption on Neem (Azadirachta indica) leaf powder. Dyes Pigm 65:51-59

Brown D (1987) Effects of colorants in the aquatic environment. Ecotoxicol Environ Saf 13:139-147

Caner N, Kiran I, Illhan S, Iscen C (2009) Isotherm and kinetic studies of burazol blueed dye biosorption by dried anaerobic sludge. J Hazard Mater 165:279-284

Deniz F, Saygideger S (2010) Investigation of adsorption characteristics of basic red 46 onto gypsum: equilibrium, kinetic and thermodynamic studies. Desalination 262:161-165

Fan L, Zhou Y, Yang W, Chen G, Yang F (2008) Electrochemical degradation of aqueous solution of Amaranth azo dye on ACF under potentiostatic model. Dyes Pigm 76:440-446

Giannakoudakis D, Kyzas G, Avranas A, Lazaridis N (2016) Multiparametric adsorption effects of the reactive dye removal with commercial activated carbons. J Mol Liq 213:381-389

Goswami M, Phukan P (2017) Enhanced adsorption of cationic dyes using sulfonic acid modified activated carbon. J Environ Chem Eng 5:3508-3517

Gotoh T, Matsushima K, Kikuchi K (2004) Adsorption of $\mathrm{Cu}$ and $\mathrm{Mn}$ on covalently cross-linked alginate gel beads. Chemosphere 55:57-64

Gou J, Lua A (2003) Textural and chemical properties of adsorbent prepared from palm shell by phosphoric acid activation. Mater Chem Phys 80:114-119

Hameed B (2009) Evaluation of papaya seeds as a novel non-conventional low-cost adsorbent for removal of methylene blue. J Hazard Mater 162:939-944

Hameed K, Muthirulan P, Sundaram M (2017) Adsorption of chromotrope dye onto activated carbons obtained from the seeds of 
various plants: Equilibrium and kinetics studies. Arab J Chem 10:S2225-S2233

Hasnat M, Siddiquey IA, Nuruddin A (2005) Comparative photocatalytic studies of degradation of a cationic and an anionic dye. Dyes Pigm 66:185-188

Hasnat M, Uddin M, Samed A, Alam S, Hossain S (2007) Adsorption and photocatalytic decolorization of a synthetic dye erythrosine on anatase $\mathrm{TiO}_{2}$ and $\mathrm{ZnO}$ surfaces. J Hazard Mater 147:471-477

Hasnat M, Safwan J, Islam M et al (2015) Electrochemical decolorization of Methylene blue at Pt electrode in $\mathrm{KCl}$ solution for environmental remediation. J Ind Eng Chem 21:787-791

Ho Y, Mckay G (1999) The sorption of lead(II) ions on peat. Water Res 33:578-584

Islam M, Ali I, Karim S, Firoz M et al (2019) Removal of dye from polluted water using novel nano manganese oxide-based materials. J Water Process Eng 32:100911

Kannan K, Sundaram M (2001) Kinetics and mechanism of removal of methylene blue by adsorption on various carbons-a comparative study. Dyes Pigm 51:25-40

Kim Y, Ogata T, Nakano T (2007) Kinetic analysis of palladium(II) adsorption process on condensed-tannin gel based on redox reaction models. Water Res 41:3043-3050

Klimmek S, Stan H, Wilke A, Bunke G, Buchholz R (2001) Comparative analysis of the biosorption of Cadmium, Lead, Nickel, and Zinc by Algae. Environ Sci Technol 35:4283-4288

Kumar P, Varjani S, Suganya S (2018) Treatment of dye wastewater using an ultrasonic aided nanoparticle stacked activated carbon: Kinetic and isotherm modelling. Bioresour Technol 250:716-722

Magdy Y, Altaher H (2018) Kinetic analysis of the adsorption of dyes from high strength wastewater on cement kiln dust. J Environ Chem Eng 6:834-841

Malik P (2004) Dye removal from wastewater using activated carbon developed from sawdust: adsorption equilibrium and kinetics. J Hazard Mater 113:81-88

Mall ID, Srivastava V, Agarwal N (2007) Adsorptive removal of Auramine-O: Kinetic and equilibrium study. J Hazard Mater 143:386-395

Mittal A, Gajbe V, Mittal J (2008) Removal and recovery of hazardous triphenylmethane dye, Methyl Violet through adsorption over granulated waste materials. J Hazard Mater 150:364-375

Miyah Y, Lahrichi A, Idrissi M, Khalil A, Zerrouq F (2018) Adsorption of methylene blue dye from aqueous solutions onto walnut shells powder: equilibrium and kinetic studies. Surf Interfaces 11:74-81

Nissinen T, Li M, Brielles N, Manna S (2013) Calcium sulfate hemihydrate-mediated crystallization of gypsum on $\mathrm{Ca}^{2+}$-activated cellulose thin films. CrystEngComm 15:3793-3798

Panday K, Prasad G, Singh V (1985) Copper(II) removal from aqueous solutions by fly ash. Water Res 19:869-873
Rahman M (2011) Adsorption behaviors of Brilliant Red on Tannin Gel and Amine Modified Tannin Gel. M. Sc. Thesis, Physical Chemistry Lab. SUST. 3:54-77

Rahman MM, Akter N, Karim M et al (2014) Optimization, kinetic and thermodynamic studies for removal of Brilliant Red (X-3B) using Tannin gel. J Environ Chem Eng 2:76-83

Raii M, Sanz F, Nzihou A (2012) Rheological behavior of Gypsum, Plaster, and Hydroxyapatite Gel Blends. Ind Eng Chem Res 51:11163-11169

Rao R, Khan M (2009) Biosorption of bivalent metal ions from aqueous solution by an agricultural waste: kinetics, thermodynamics and environmental effects. Colloids Surf 332:121-128

Rauf M, Qadri S, Ashraf S, Al-Mansoori K (2009) Adsorption studies of Toluidine Blue from aqueous solutions onto gypsum. Chem Eng J 150:90-95

Sengil I, Ozacar M (2008) Biosorption of Cu(II) from aqueous solutions by mimosa tannin gel. J Hazard Mater 157:277-285

Silva JP, Sousa S, Roodrigues J et al (2004) Adsorption of acid orange 7 dye in aqueous solutions by spent brewery grains. Sep Purif Technol 40:309-315

Sivaraj R, Namasivayam C, Kadirvelu K (2001) Orange peel as an adsorbent in the removal of Acid violet 17 (acid dye) from aqueous solutions. Waste Manag 21:105-110

Tutem E, Apak R, Unal C (1998) Adsorptive removal of chlorophenols from water by bituminous shale. Water Res 32:2315-2324

Uddin M, Islam M, Mahmud S, Rukanuzzaman M (2009) Adsorptive removal of methylene blue by tea waste. J Hazard Mater 164:53-60

Wang S, Zhu ZH, Coomes A, Haghseresh F, Lu GQ (2005) The physical and surface chemical characteristics of activated carbons and the adsorption of methylene blue from wastewater. J Colloid Interface Sci 284:440-446

Yagub M, Sen T, Afroze S, Ang H (2014) Dye and its removal from aqueous solution by adsorption: a review. Adv Colloid Interface Sci 209:172-184

Yan Y, Dong X, Sun XI et al (2014) Conversion of waste FGD gypsum into hydroxyapatite for removal of $\mathrm{Pb}^{2+}$ and $\mathrm{Cd}^{2+}$ from wastewater. J Colloid Interface Sci 429:68-76

Youcef L, Belaroui L, López-Galindo A (2019) Adsorption of a cationic methylene blue dye on an Algerian palygorskite. Appl Clay Sci 179:105145

Publisher's Note Springer Nature remains neutral with regard to jurisdictional claims in published maps and institutional affiliations. 